\title{
The Decrease In The Anxiolytic Effect of Morphine After Repeated Use of The Drug In Rats is Associated With Inflammatory Cytokine Signaling Pathways In The Prefrontal Cortex
}

\section{Shamseddin Ahmadi ( $\nabla$ sh.ahmadi@uok.ac.ir)}

University of Kurdistan https://orcid.org/0000-0003-0300-3226

Shiva Mohammadi Talvar

University of Kurdistan

Kayvan Masoudi

University of Kurdistan

Mohammad Zobeiri

University of Kurdistan

\section{Research Article}

Keywords: Anxiety-like behaviors, Morphine dependence, Gene expression, Neuroinflammation, Toll-like receptor, Interleukin-1

Posted Date: September 27th, 2021

DOI: https://doi.org/10.21203/rs.3.rs-884648/v1

License: (9) This work is licensed under a Creative Commons Attribution 4.0 International License.

Read Full License 


\section{Abstract}

We aim to examine anxiety-like behaviors and expression of specific genes complicated in neuroinflammation in the prefrontal cortex (PFC) after repeated use of morphine. A group of male Wistar rats received injections of morphine $(10 \mathrm{mg} / \mathrm{kg})$ twice a day for eight days while a control group received saline $(1 \mathrm{ml} / \mathrm{kg})$ instead of morphine. On days 1 and 8 , anxiety-like behaviors were evaluated using a light/dark box test. On day 8, opioid dependence was confirmed by measuring the behavioral expression of morphine withdrawal precipitated with naloxone. Expression of neuroinflammation genes were also evaluated at mRNA levels in the PFC on day 8 . The results revealed that morphine induced anxiolytic-like effects on day 1 , which significantly decreased after the repeated injection of the drug on day 8 . The results also revealed that repeated morphine injection significantly increased the mRNA level of $/ / 1, T n f a$, and $/ / 6$ but decreased $/ / 1 r$ and Tnfr while increased $/ / 6 r$ in the PFC. The gene expression results also revealed a significant decrease in T/r1 but not in TIr4 in the PFC of morphine-dependent rats. Although Erk 1 expression had no significant alteration but $p 38$ increased and Jnk3 decreased significantly in the PFC in morphine-dependent rats. Creb and $N f k b$ significantly increased but Fos expression decreased. Let-7c, mir-133b, and mir-365 also significantly increased in the PFC in morphine-dependent rats. We conclude that the alteration in neuroinflammatory pathways at gene expression level in the PFC may party underlie neuroadaptive changes leading to the decrease in anxiolytic effect of morphine in dependent rats.

\section{Introduction}

Opioids, such as morphine mainly are used for pain control but their prolonged use not only increases the risk of analgesic tolerance but also induces dependence (Ueda and Ueda 2009; Watkins et al. 2009). Acute morphine administration has also anxiolytic-like effects (Glover and Davis 2008) but chronic use of the drug induces anxiety (Motaghinejad et al. 2015). Neuronal alteration and adaptions at both cellular and molecular levels in neurons and synapses in different levels of the central nervous system (Bali and Kenny 2019; Robinson and Kolb 2004; Yu et al. 2014), may underlie tolerance, dependence, and anxiety induced by morphine (Koller et al. 2019; Mercadante et al. 2019; Wilson-Poe et al. 2017). It is well-known that rewarding properties of morphine leading to drug dependence is mediated via disinhibition of the mesolimbic dopaminergic pathway originating from the ventral tegmental area (VTA) projecting to some forebrain areas, including the nucleus accumbens (NAc), the prefrontal cortex (PFC), and the hippocampus (Kim et al. 2016; Koob and Volkow 2016). The forebrain areas such as the PFC, via descending excitatory glutamatergic projections, also modulate the processing of reward stimuli in the VTA and the NAc (Kelley and Domesick 1982; Sesack and Pickel 1990).

The PFC includes the anterior portion of the frontal lobe that has executive functions such as planning, problem-solving, and social control (Dixon et al. 2017; Ong et al. 2019). The PFC not only is important in executive functions but also has a prominent role in pain processing (Ong et al. 2019). Numerous studies have also shown that the PFC via having interconnections with structures including the amygdala, the bed nucleus of the stria terminalis, and the ventral hippocampus involved in processing information 
related to anxiety (Adhikari et al. 2010; Lowery-Gionta et al. 2018). Neural circuitry and molecular profiles of the PFC can be changed by experiences, which influence its functions (McEwen and Morrison 2013). Since the PFC is directly and indirectly affected by repeated use of morphine (Koob and Volkow, 2010; Quirion et al., 1983), it may have important roles in morphine side effects, including cognitive impairment and anxiety.

At the molecular level, opioids modify gene expression profile in the brain reward regions, such as the PFC, and these alterations are considered as the origins of the structural and functional remodeling of the reward pathway after chronic use of drugs (Ahmadi et al. 2016; Ammon-Treiber and Hollt 2005; Sepehrizadeh et al. 2008). The actions of morphine on neurons mainly are mediated by mu-opioid receptors (Listos et al. 2019; Spetea et al. 2013). However, a growing body of evidence shows that morphine also activates glial cells, including microglia and astrocytes (Eidson and Murphy 2013; Eidson and Murphy 2019; Song and Zhao 2001). Accumulating evidence shows that morphine affects glial cells by binding to immune cells toll-like receptor 4 (TLR4), leading to the release of proinflammatory cytokines, which in turn affect the neuronal transmission and plasticity involved in opioid functions (Eidson and Murphy 2013; Wu and Li 2020). Based on the evidence in the literature of the past two decades, it is logical to say that immune signaling is a significant contributor to the negative consequences of opioid therapy including hyperalgesia, tolerance, dependence, addiction, and withdrawal (Eidson and Murphy 2013; Eidson and Murphy 2019; Jacobsen et al. 2014; Song and Zhao 2001; Wu and Li 2020). However, little is known on the role of inflammatory cytokines and immune signaling in different brain areas on anxiety-like behaviors induced by prolonged use of morphine.

This study aimed to examine gene expression of toll-like receptors, proinflammatory cytokines, and their receptors, and downstream signaling molecules in the PFC after repeated morphine injection to assess their involvement in anxiety-like behaviors in rats. Different microRNAs (miRNAs) have also been identified to be affected with chronic use of morphine (Barbierato et al. 2015; Huang et al. 2019). Based on target gene prediction for miRNAs, we also examined the expression of pre-miRNAs for let7-C1, mir$133 \mathrm{~b}$, and mir-365, which have a putative role to modulate the expression of inflammatory cytokine receptors.

\section{Materials \& Methods}

\section{Subjects}

Sixteen male Wistar rats (Rattus norvegicus) weighing $280 \pm 20 \mathrm{~g}$ were used. Rats were kept in a colony room under constant temperature $\left(22 \pm 2{ }^{\circ} \mathrm{C}\right)$ and $12-12 \mathrm{~h}$ light/dark cycle (light off at 19:00). The animals had free access to food and water except during the behavioral experiments. All efforts were made to minimize the number of animals used and their suffering. All procedures were done according to the Guide for the Care and Use of Laboratory Animals (2011) prepared by the National Academy of Sciences' Institute for Laboratory Animal Research. The Research Ethics Committee (REC) at the University of Kurdistan approved the study protocol (IR.UOK.REC.1398.021). 


\section{Drug treatment}

Animals were randomly assigned to either a control saline-treated or a morphine-treated group. Morphine sulfate (Temad, Daroopakhsh Co., Tehran, Iran) was dissolved in physiologic saline and the morphinetreated group received a subcutaneous injection of morphine $(10 \mathrm{mg} / \mathrm{ml} / \mathrm{kg})$ twice a day for eight consecutive days. The control group received saline $(1 \mathrm{ml} / \mathrm{kg})$ instead of morphine during the eight days of the treatment period.

\section{Light and dark box test of anxiety}

Anxiety-like behaviors were examined with a light/dark box test of anxiety based on our previous report (Ahmadi and Khaledi 2020). The apparatus consisted of a light chamber $(30 \star 30 \star 24 \mathrm{~cm})$ and a dark chamber $(20 * 30 * 24 \mathrm{~cm})$. The floors of the chambers were marked off in nine and six squares $(10 \times 10$ $\mathrm{cm})$, respectively. A white light source ( $6 \mathrm{~W}$ ) lit the light chamber, whereas the dark chamber was illuminated by a dim red-light source $(3 \mathrm{~W})$, which both of them placed $40 \mathrm{~cm}$ above the floor of the chambers. The height of the dividing wall between the two chambers was $40 \mathrm{~cm}$ to prevent the emission of the light sources into the opposite chamber. A connecting door $(10 \times 10 \mathrm{~cm})$ in the middle and at the floor level of the dividing wall permits voluntary transitions of the animals between the chambers. The floor and wall of both chambers were made of Plexiglass and cleaned between trials with an ethanol solution ( $10 \% \mathrm{v} / \mathrm{v})$ and dried fully before the testing. Thirty min after the drug treatments at the morning session on days 1 and 8, the light/dark test was performed for each rat. The test started when each rat was placed in the center of the white area facing away from the middle door and was allowed for 5 min exploring the apparatus. Each animal was videotaped during the $5 \mathrm{~min}$ of exploration through a video camera fixed above the apparatus (100 cm from the floor of the apparatus). Then, the videos were analyzed by a researcher blinded to experimental groups and different parameters including 1) lightbox time spent, 2) the number of squares crossing as an index of locomotor activity, and 3) the number of rearing behavior in the white chamber, as well as 4) the total crossing or transitions between the two chambers were evaluated (Bourin and Hascoet 2003; Costall et al. 1989; Ramos 2008).

\section{Naloxone-precipitated withdrawal test}

We assessed the induction of morphine dependence by measuring the behavioral expression of morphine withdrawal precipitated with naloxone on day 8 of the injections. In two independent groups of animals, naloxone hydrochloride ( $1 \mathrm{mg} / \mathrm{kg}$, i.p.) was intraperitoneally injected $4 \mathrm{~h}$ after injection of saline or morphine at the morning session on day 8 (Yu et al. 2014). Each rat was immediately after the naloxone injection moved to a square clear Plexiglass chamber $(40 \times 40 \times 40 \mathrm{~cm}$ high), and was videotaped for 15 mins with two video cameras (Sony, Japan). Two classes of signs, including graded and checked signs, were evaluated and scored as described elsewhere (Table 1) (Yu et al. 2014). The somatic signs of withdrawal were recorded as the number of events observed during 15 mins of the recorded experiment.

\section{Brain dissections}


In two experimental groups, two $\mathrm{h}$ after completion of the light/dark box test on day 8, each rat was decapitated, the whole brain was quickly removed from the skull, and the bilateral PFCs were immediately dissected on an ice-chilled sterile surface (Ahmadi et al. 2015a; Ahmadi et al. 2015b; Chiu et al. 2007). Tissues were immediately frozen in liquid nitrogen and stored in a -80 freezer until using for molecular analysis.

\section{Real-time polymerase chain reaction}

Total RNA was extracted by using a commercial kit according to the manufacturer's supplied protocol (High Pure miRNA isolation kit, Roche, Germany). The total RNAs were reverse transcribed to complementary DNA (cDNA) by using a two-step cDNA synthesis kit according to the manual provided by the manufacturer (First Strand cDNA Synthesis Kit, Thermo Fisher Scientific, USA). Real-time PCR was performed using LightCycler 96 system thermal cycler (Roche, Germany). Each PCR reaction of $20 \mu \mathrm{l}$ volume consisted of $10 \mu$ ITA SYBR Green qPCR MasterMix (Yekta Tajhiz Azma Co., Tehran, Iran), $8 \mu \mathrm{l}$ cDNA $(4 \mathrm{ng} / \mu \mathrm{l}), 2 \mu \mathrm{lmix}$ of the forward and reverse primers $(5 \mu \mathrm{M})$. Triplicate technical repeats were determined for each biological sample. Thermal cycling was initiated with a pre-incubation step $\left(95^{\circ} \mathrm{C}\right.$ for $30 \mathrm{Sec}$ ), followed by 40 cycles of two-step amplification $\left(95^{\circ} \mathrm{C}\right.$ for $5 \mathrm{Sec}$ and $60^{\circ} \mathrm{C}$ for $30 \mathrm{Sec}$ ), followed by melting $\left(95^{\circ} \mathrm{C}\right.$ for $5 \mathrm{Sec}, 60^{\circ} \mathrm{C}$ for $60 \mathrm{Sec}$, and $95^{\circ} \mathrm{C}$ for $\left.1 \mathrm{Sec}\right)$, and finalized by cooling at $50^{\circ} \mathrm{C}$ for $30 \mathrm{Sec}$. We used the $2^{-\triangle \Delta C T}$ method to assess relative gene expression (Livak and Schmittgen 2001). Glyceraldehyde 3-phosphate dehydrogenase (Gapdh) was selected as a housekeeping gene and was used for normalization. The sequences of PCR primers and the respective amplicon sizes have been summarized in Table 2.

\section{Statistical analysis}

We examined the normality of the data with the Shapiro-Wilk test and assessed equality of variance with the Brown-Forsythe test. All data passed normality and equal variance tests. A mixed between-within subject's ANOVA with two factors, including "the drug" with two levels (saline and morphine) and "days of testing" with two levels (days 1 and 8) was performed for analyzing anxiety-like behaviors. Post hoc Tukey's test was used for pairwise comparisons. An unpaired two-tailed Student t-test was used to analyze naloxone precipitated withdrawal symptoms and gene expression data. $P<0.05$ was considered as a statistically significant level. Data analysis and plotting data were done using GraphPad Prism version 9.0. The corresponding author is responsible for data sharing upon reasonable request.

\section{Results}

Morphine administration induced anxiolytic-like effects on day 1 , which was significantly decreased on day 8 of the repeated injection

The light/dark box test is based on an approach-avoidance conflict between exploration of novel environments and avoidance of a brightly lit open space. In this test, a higher time spent in the lightbox is interpreted as lower anxiety in the rats. The results revealed a significant interaction between the 
morphine treatment and days of testing on total time spent in the lightbox $[F(1,14)=66, \mathrm{P}<0.001]$. The main effects for both factors on total time spent in the lightbox were also significant; for drug $[F(1,14)=$ $88, P<0.001]$, and for days of testing $[F(1,14)=139, P<0.001]$. According to the post hoc Tukey's test, morphine induces anxiolytic-like effects on day 1 compared with the saline-treated group $(P<0.001)$. However, morphine after the repeated injections induces anxiety revealed by a significant decrease in lightbox time spent and locomotion compared with the saline-treated control group on day $8(P<0.001)$.

The results also revealed a significant interaction between both factors on the number of locomotor activity in the light box $[F(1,14)=57, \mathrm{P}<0.001]$. The main effects for both factors, including the drug and days of testing on locomotion in the light box were also significant; for drug $[F(1,14)=91, P<0.001]$, and for days of testing $[F(1,14)=18, P<0.001]$. The results revealed no significant interaction between both factors on rearing behavior in the light box $[F(1,14)=0.7, \mathrm{P}>0.05]$. The main effect of days of testing on rearing behavior in the light box was also not significant $[F(1,14)=4.4, P>0.05]$, but the main effect of drug on rearing behavior in the light box was significant $[F(1,14)=14, P<0.01]$. The results also indicated a significant interaction between the morphine treatment and days of testing on crossing between light and dark boxes $[F(1,14)=39, \mathrm{P}<0.001]$. The main effects for both factors on crossing or transitions between both boxes were also significant; for drug $[F(1,14)=20, P<0.001]$, and for days of testing $[F(1,14)=58, P<0.001]$ (Fig. 1).

\section{Naloxone precipitated withdrawal expressions confirmed morphine dependence after 8 days of repeated administration of the drug}

On day 8 of the repeated injection, naloxone-precipitated withdrawal symptoms were assessed to confirm dependence to morphine in two independent experimental groups. The results of independent sample ttest revealed significant increases in the number of all withdrawal graded signs, including locomotor activity [t $(14)=5.1, P<0.001]$, rearing [t $(14)=9.6, P<0.001]$, jumping [ $t(14)=6.2, P<0.001]$, writhing [t $(14)=9.8, P<0.001]$, rubbing $[t(14)=11.3, P<0.001]$, and shaking $[t(14)=5.6, P<0.001]$, as well as the total withdrawal score $[\mathrm{t}(14)=9.9, \mathrm{P}<0.001]$ in morphine-treated group compared with saline-treated control group (Fig. 2).

The TIr1 gene expression decreased but the TIr4 gene expression did not significantly alter in the PFC after repeated injection of morphine

We examined gene expression of toll-like receptor 1 (TIr1) and TIr4 in the PFC after 8 days of the repeated injection of morphine. Analysis of the qPCR results revealed that the TIr1 gene expression significantly decreased [ $\mathrm{t}(14)=3.8, \mathrm{P}<0.01]$ but no significant alteration was detected for $T / r 4$ gene expression [ $\mathrm{t}$ (14) $=0.4, \mathrm{P}>0.05]$ in the PFC in morphine-treated group compared with saline-treated control group (Fig. 3).

The $\| 1$, Tnfa, and 116 gene expression increased but gene expression of their receptors except for $\| 6 r$ decreased in the PFC after repeated injection of morphine 
We examined gene expression of proinflammatory cytokines, including /17, Tnfa, //6 and their respective receptors, including $/ / 1 r$, Tnfr, and $/ / 6 r$ in the PFC after 8 days of the repeated injection of morphine. Analysis of the qPCR data revealed significant increases in the gene expression of $/ / 1$ [t $(14)=13.04, P<$ 0.001], Tnfa [t $(14)=5.4, \mathrm{P}<0.001]$, and $/ 16$ [t $(14)=5.3, \mathrm{P}<0.001]$ compared with the saline-treated control group. The results also revealed that the gene expression of $/ 11 r[\mathrm{t}(14)=6.2, \mathrm{P}<0.001]$ and $\operatorname{Tnfr}[\mathrm{t}(14)=$ $5.5, P<0.001]$ significantly decreased but the $/ / 6 r$ gene expression $[t(14)=4.7, P<0.001]$ significantly increased in morphine-treated group compared with the saline-treated control group (Fig. 4).

Repeated injection of morphine had no effect on Erk1 gene expression but significantly increased the p38 gene expression and decreased Jnk3 gene expression in the PFC

Protein kinases are considered as key modulators of the cellular adaptations associated with opioid tolerance and dependence (Liu and Anand 2001). We examined the expression of mitogen-activated protein kinases (MAPK), including Erk1, p38a, and Jnk3 MAPKs in the PFC after 8 days of repeated administration of morphine. Analysis of the qPCR results revealed a significant increase in $p 38 a$ gene expression [t $(14)=13.5, P<0.001]$ but a significant downregulation in Jnk3 gene expression [t $(14)=6.2$, $\mathrm{P}<0.001]$ in rats treated with morphine compared with saline-treated group. However, no group difference was detected for Erk1 gene expression between the experimental groups [t (14) $=1.9, P>0.05]$ (Fig. 5).

Repeated injection of morphine increased gene expression of Creb1 and Nfkb but decreased the Fos gene expression in the PFC

A growing body of researches shows the effects of chronic morphine treatment on gene expression are mediated by alterations in transcription factors (Bali and Kenny 2019; Robison and Nestler 2011). We assessed the expression of cAMP response element-binding (Creb1), nuclear factor-kappa $B(N f k b)$ and Fos proto-oncogene, AP-1 transcription factor subunit (Fos) in the PFC after 8 days repeated injection of morphine. The gene expression results revealed significant upregulation in the gene expression of $\mathrm{Creb}$ [t $(14)=12.2, \mathrm{P}<0.001]$ and $N f k b[\mathrm{t}(14)=6.3, \mathrm{P}<0.001]$ in the PFC after repeated injection of morphine compared with the saline-treated group. However, the Fos expression was significantly downregulated in the PFC after repeated injection of morphine compared with the saline-treated group Fos [t (14) $=4.2, \mathrm{P}<$ 0.001] (Fig. 6).

Repeated injection of morphine increased expression of pre-miRNAs, including Let-7c1, mir-133b, and mir365 in the PFC

A growing body of evidence supports that chronic morphine treatment affects miRNAs expression, which in turn can influence tolerance and addiction to morphine. We assessed the expression of three premiRNAs, including Let-7c1, mir-133b, and mir-365 in the PFC on day 8 of the repeated injection. The qPCR results revealed significant increases in the expression of Let-7c1 [t $(14)=10.4, \mathrm{P}<0.001$ ], mir-133b [t $(14)=10.1, P<0.001]$, and mir-365 [t $(14)=10.9, P<0.001]$ in the PFC after repeated injection of morphine compared with the saline-treated group (Fig. 7). 


\section{Discussion}

Morphine is still the first choice for controlling chronic pain in the clinic. Unfortunately, besides tolerance to the analgesic effect of morphine, anxiety has been described as an important comorbidity in patients suffering from chronic pain (Roeska et al. 2008). The present results revealed that morphine induces anxiolytic-like behaviors on day 1 of the repeated injection as revealed by a significant increase in lightbox time spent compared with the saline-treated rats. On day 1, consistent with the increased lightbox time spent, the locomotor activity of the animals in the lightbox significantly increased compared with the saline-treated control group. This significant increase in locomotion in the lightbox on day 1 discards the possibility of freezing behavior in the lightbox and further supports anxiolytic-like effects of morphine on day 1 . However, rearing behavior in the lightbox and crossing between two chambers in morphine-treated animals showed a tendency to increase compared with the saline-treated animals but no significant alteration was detected on day 1 . On contrary, repeated morphine injection induced anxietylike behaviors on day 8 of the treatment as revealed by significant decreases in lightbox time spent and locomotion in the light chamber compared with the saline-treated animals. However, on day 8 , the number of crossing between light and dark chambers in the morphine-treated group was significantly higher than its respected number on day 1 , which may also reflect an increase in anxiety or a decrease in anxiolyticlike effects after 8 days of repeated injection of morphine due to approach-avoidance conflict between exploration of both chambers. According to research, morphine shows anxiolytic-like properties during initial exposure, which is modulated by nitric oxide (NO) systems (Shin et al. 2003). However, in line with the present results, other investigators have also reported anxiety-like behaviors after chronic administration of morphine (Lee et al. 2012; Miladi-Gorji et al. 2012).

The present results also indicate that repeated administration of morphine induces drug dependence as revealed by significant withdrawal signs induced by naloxone precipitation on day 8 of the repeated injections of morphine. Therefore, besides depression and cognitive dysfunctions, anxiety-like behaviors can be considered among undesired outcomes of morphine dependency (Jarvik et al. 1981; Motaghinejad et al. 2016; Niu et al. 2017). The amygdala functions to detect the threat and generate emotions such as fear and anxiety, whereas the PFC and hippocampus function to downregulate the amygdala (Mah et al. 2016). Exposure to drugs of abuse may cause a reorganization of molecular patterns in the PFC that alter the responsiveness of the PFC to reward inputs and also the firing of neurons projected from the PFC to the other limbic structures such as the amygdala (Quintero 2013; Wang et al. 2019). Therefore, further analyses of molecular pathways in the PFC are important to understand the mechanisms resulting in the development of morphine dependence and the decrease in its anxiolytic-like effects after prolonged use of the drug. Activation of glia by morphine via binding to tolllike receptors has attracted considerable attention to explain, at least partly, non-neuronal mechanisms of the induction of tolerance and dependence to morphine (Eidson and Murphy 2013; Eidson and Murphy 2019; Hutchinson et al. 2011; Wu and Li 2020). However, little is known about the involvement of neuroinflammation pathways upon activation of toll-like receptors and production of inflammatory cytokines in anxiety-like behaviors after repeated injection of morphine. 
The involvement of TLR2 and TLR4 in the development of morphine tolerance and dependence has been previously reported (Eidson and Murphy 2013; Zhang et al. 2011b). However, there are not considerable reports on the involvement of TLR1 in morphine functions. The present results indicated downregulation of TIr1 in the PFC after prolonged morphine injections for 8 days. However, no significant alteration was detected in the T/r4 gene expression after repeated injection of morphine. The gene expression results in the present experiments also revealed significant increases in $I / 1$, Tnfa, and $I / 6$ expression in the PFC after repeated morphine treatment compared with saline-treated group. On contrary, I/1r and Tnfr were downregulated but //6rwas upregulated in the PFC in morphine-dependent rats. It has been shown that prolonged administration of morphine is followed by less effective opioid actions (Benyamin et al. 2008). Accumulating data shows that the ineffectiveness of morphine is results from adaptation within opioid receptor-expressing neurons in the reward pathways. However, this adaptation is not only restricted to neurons but also activation of glial cells by morphine, and subsequent production of proinflammatory cytokines is considered as an alternate process affecting morphine actions. Therefore, the role of glia and TLR4 in the development of morphine tolerance and addiction during the past two decades has been postulated and recently reviewed (Eidson and Murphy 2019; Wu and Li 2020). The present results may support the involvement of TLR1 in morphine actions in the PFC. Besides, activation of glia in the PFC after repeated morphine treatment in rats is proposed as revealed by the upregulation of proinflammatory cytokines. On the other hand, downregulation of I/1rand Tnfr may serve as homeostatic adaptations in response to the increased level of these cytokines due to repeated administration of morphine. The central immune signaling profoundly affects behavioral responses in the brain (Hutchinson et al. 2011). Therefore, the increases in anxiety-like behaviors after repeated use of morphine may result, at least partly, from the altered cytokine levels and their contribution to neuroexitability in the PFC. In support of this suggestion, it has been reported that IL-1 $\beta$ can, directly and indirectly, increase NMDA receptor activity, which may also contribute to neuroexcitation (Hutchinson et al. 2011). However, we did not examine protein levels of these molecules and neurotransmitter levels, and further studies are needed to confirm this hypothesis.

A growing body of evidence shows that chronic morphine administration influences different protein kinases, including MAPKs (Liu and Anand 2001). We examined gene expression of Erk1, p38a, and Jnk3 MAPKs in the PFC after the repeated injection of morphine. The results revealed no significant alteration in Erk1 gene expression but p38a gene expression significantly increased and Jnk3 gene expression significantly decreased in the PFC in morphine-treated animals. The present data support the involvement of p38 and JNK3 MAPKs in neuronal adaptations after repeated morphine treatment in the PFC (Chen and Sommer 2009). Chronic exposure to morphine leads to phosphorylation and binding of arrestin protein to the opioid receptors (Allouche et al. 2014). Phosphorylated arrestin-bound opioid receptors in neurons recruit alternate downstream signaling cascades, including the MAPK cascade (Corder et al. 2018; Law et al. 2000), which may regulate transcription factors, ion channels, and neurotransmitter release (Raman et al. 2007). A clear role for JNK signaling pathways in morphine tolerance has been reported (Yuill et al. 2016). Inhibition of the JNK signaling pathway delays tolerance to the antinociceptive effects of chronic morphine in diverse pain models (Marcus et al. 2015). Therefore, 
chronic administration of morphine via a MAPK cascade may alter the expression of proinflammatory cytokines, which in turn via perturbation in neurotransmission and firing of the PFC outputs may affect anxiety-like behaviors.

There is some evidence that shows ERK is involved in the analgesic and hyperalgesic effects of acute morphine while p38, JNK, and CREB are involved in delayed hyperalgesia induced by the opioid (de Freitas et al. 2019). There is not enough report on the role of JNK3 in the PFC in behavioral alteration after morphine treatment. We have reported recently downregulation of Jnk3 in the PFC in a rat model of hepatic encephalopathy (Ahmadi et al. 2020). Since the role of neuroinflammation has been verified in hepatic encephalopathy, so the decreased Jnk3 gene expression in the PFC may reflect induction of neuroinflammation after repeated injection of morphine. Considering the increased expression of inflammatory cytokines in the present study, the downregulation of Jnk3 may play as a compensatory response to prevent further neuroexcitation induced by cytokines.

Activation of p38 MAPK in the spinal microglia mediates morphine antinociceptive tolerance (Cui et al. 2006), and its inhibition prevents the antinociceptive tolerance induced by the drug (Cui et al. 2008). p38 MAPK signaling pathway in the NAc is also involved in the induction of conditioned place preference (Hong et al. 2017). However, little is known about the role of p38 MAPK in the PFC in anxiety-like behaviors after prolonged treatment of morphine. It is possible that inhibition of cytokine signaling and MAPKs pathway especially p38 MAPK also be useful in the prevention of dependence to morphine and the anxiety-like behaviors after repeated use of the drug.

The present results also revealed that Creb1 and Nfkb expression in the PFC increased but Fos expression decreased after repeated injection of morphine. CREB is a target for opioid-regulated secondary messengers to alter gene expression (Bilecki and Przewłocki 2000), and thereby may regulate different adaptive responses, including emotional behavior and drug addiction (Valverde et al. 2004). Activation of the p38/NF-kB signaling pathway in the NAc plays a critical role in morphine conditioned place preference (Zhang et al. 2011a). The expression of both proinflammatory cytokine genes such as //1 and Tnfa is dependent on the activation of NF-KB. Neuronal CREB has a selective role in anxiety-like behavior and the somatic expression of morphine withdrawal, without participating in the rewarding properties induced by morphine (Valverde et al. 2004). It is logical to propose that the increase in the gene expression of $N f k b$ is in line with the increased level of the above-mentioned cytokines as seen in the present experiments.

miRNAs have been reported to be involved in morphine analgesic tolerance and addiction (Sartor et al. 2012; Zhang et al. 2019). The present results also revealed that expression of pre-miRNAs, including Let7c1, mir-133b, and mir-365 were significantly upregulated in the PFC after induction of morphine dependence. The Let-7 family of miRNAs has a critical regulatory role in opioid tolerance (He and Wang 2012). Consistent with the present results, He et. al. (2010) reported that morphine significantly upregulated let-7 expression in SH-SY5Y cells and a mouse model of opioid tolerance (He et al. 2010). Mir-133b via affecting dopaminergic neurons may be a regulatory mechanism for the development of 
addiction to morphine (García-Pérez et al. 2015; Rodríguez 2012). However, there is no report on mir-133b expression in the PFC after repeated use of morphine. Considering the putative targets of mir-133b and mir-365 such as I/1rand Tnf family receptors based on TargetScan target gene prediction, we suggest that the increased level of mir-133b and mir-365, at least partly, be also involved in the downregulation of these receptors in the PFC. However, further experiments may require clarifing the exact effects of these miRNAs on the expression of the proposed targets, and also affecting other target genes cannot be excluded, which needs further experiments in the future.

\section{Conclusions}

The present data revealed that prolonged morphine injection not only induces dependence on the drug but also decreases the anxiolytic effects of the drug on day 8 compared with day 1 of the injections. At gene expression level, alteration in proinflammatory cytokines including $\|1\| 6$, Tnfa, and their respective receptors, TIr1, p38 and Jnk3 MAPKs, Creb, Nfkb, and Fos transcription factors as well as a few miRNAs including Let-7c1, mir-133b, and mir-365, were detected in the PFC after repeated morphine injection. It must be noticed that for many genes, transcript and protein levels do not correlate well (Tian et al. 2004), and therefore, examining protein levels of the examined receptors and downstream molecules is a limitation of our study and is suggested for future research. However, the alteration at the mRNA level has its own impact on the subsequent cellular and molecular processes in brain regions that may affect neural adaptations. Finally, considering the examined genes in the present experiments, it seems that alterations in the inflammatory signaling pathways either in neurons or in glia in the PFC after prolonged morphine treatment may affect a top-down neural system originating from the PFC projecting to the amygdala, which in turn affects emotional processing such as anxiety. However, future researches need to be conducted to examine this possibility.

\section{Declarations}

Acknowledgment: This research was funded by the Cognitive Sciences and Technologies Council of Iran (Contract No. D/100/11988).

\section{Ethics approval}

All procedures were done according to the Guide for the Care and Use of Laboratory Animals (2011) prepared by the National Academy of Sciences' Institute for Laboratory Animal Research. The Research Ethics Committee (REC) at the University of Kurdistan approved the study protocol (IR.UOK.REC.1398.021).

\section{Authors contribution}

Shamseddin Ahmadi: Conceptualization and design of the work, Writing- Original Draft Preparation, Writing- Reviewing and Editing, Supervision, Project Administration, Funding Acquisition. Mohammad 
Zobeiri, Shiva Mohammadi Talvar, Kayvan Masoudi: Acquisition, analysis, interpretation of data, and Writing- Original Draft Preparation. All authors approved the final version for publication.

\section{Funding}

This study was funded by Cognitive Sciences and Technologies Council of Iran (Contract No.

D/100/11988).

\section{Conflicts of interests}

The author(s) declare no potential conflicts of interest concerning the research, authorship, and/or publication of this article.

\section{Data availability}

The datasets generated during and/or analysed during the current study are available from the corresponding author on reasonable request.

\section{References}

1. Adhikari A, Topiwala MA, Gordon JA (2010) Synchronized activity between the ventral hippocampus and the medial prefrontal cortex during anxiety. Neuron 65:257-269

2. Ahmadi S, Ghaderi H, Saadati N, Samadi S (2020) Mesoporous silica SBA-15 decreases hyperammonemia and affects the gene expression of mitogen-activated protein kinases in the prefrontal cortex of rats with bile duct ligation. Iran J Basic Med Sci 23:1293-1300

3. Ahmadi S, Karami Z, Mohammadian A, Khosrobakhsh F, Rostamzadeh J (2015a) Cholestasis induced antinociception and decreased gene expression of MOR1 in rat brain. Neuroscience 284:7886

4. Ahmadi S, Khaledi S (2020) Anxiety in rats with bile duct ligation is associated with activation of JNK3 mitogen-activated protein kinase in the hippocampus. Metab Brain Dis 35:579-588

5. Ahmadi S, Miraki F, Rostamzadeh J (2016) Association of morphine-induced analgesic tolerance with changes in gene expression of GluN1 and MOR1 in rat spinal cord and midbrain. Iran J Basic Med Sci 19:924-931

6. Ahmadi S, Poureidi M, Rostamzadeh J (2015b) Hepatic encephalopathy induces site-specific changes in gene expression of GluN1 subunit of NMDA receptor in rat brain. Metab Brain Dis 30:1035-1041

7. Allouche S, Noble F, Marie N (2014) Opioid receptor desensitization: mechanisms and its link to tolerance. Front Pharmacol 5:280

8. Ammon-Treiber S, Hollt V (2005) Morphine-induced changes of gene expression in the brain. Addict Biol 10:81-89 
9. Bali P, Kenny PJ (2019) Transcriptional mechanisms of drug addiction. Dialogues Clin Neurosci 21:379-387

10. Barbierato M, Zusso M, Skaper SD, Giusti P (2015) MicroRNAs: emerging role in the endogenous $\mu$ opioid system. CNS Neurol Disord Drug Targets 14:239-250

11. Benyamin R et al (2008) Opioid complications and side effects. Pain Physician 11:S105-S120

12. Bilecki W, Przewłocki R (2000) Effect of opioids on Ca2+/cAMP responsive element binding protein. Acta Neurobiol Exp (Wars) 60:557-567

13. Bourin M, Hascoet M (2003) The mouse light/dark box test. Eur J Pharmacol 463:55-65

14. Chen $Y$, Sommer $C$ (2009) The role of mitogen-activated protein kinase (MAPK) in morphine tolerance and dependence. Mol Neurobiol 40:101-107

15. Chiu K, Lau WM, Lau HT, So KF, Chang RC (2007) Micro-dissection of rat brain for RNA or protein extraction from specific brain region. J Vis Exp:269

16. Corder G, Castro DC, Bruchas MR, Scherrer G (2018) Endogenous and Exogenous Opioids in Pain. Annu Rev Neurosci 41:453-473

17. Costall B, Jones BJ, Kelly ME, Naylor RJ, Tomkins DM (1989) Exploration of mice in a black and white test box: validation as a model of anxiety. Pharmacol Biochem Behav 32:777-785

18. Cui Y, Chen Y, Zhi JL, Guo RX, Feng JQ, Chen PX (2006) Activation of p38 mitogen-activated protein kinase in spinal microglia mediates morphine antinociceptive tolerance. Brain Res 1069:235-243

19. Cui $Y$ et al (2008) A novel role of minocycline: attenuating morphine antinociceptive tolerance by inhibition of p38 MAPK in the activated spinal microglia. Brain Behav Immun 22:114-123

20. de Freitas BG, Pereira LM, Santa-Cecília FV, Hösch NG, Picolo G, Cury Y, Zambelli VO (2019) MitogenActivated Protein Kinase Signaling Mediates Morphine Induced-Delayed Hyperalgesia. Front Neurosci 13:1018

21. Dixon ML, Thiruchselvam R, Todd R, Christoff K (2017) Emotion and the prefrontal cortex: An integrative review. Psychol Bull 143:1033-1081

22. Eidson LN, Murphy AZ (2013) Blockade of Toll-like receptor 4 attenuates morphine tolerance and facilitates the pain relieving properties of morphine. J Neurosci 33:15952-15963

23. Eidson LN, Murphy AZ (2019) Inflammatory mediators of opioid tolerance: Implications for dependency and addiction. Peptides 115:51-58

24. García-Pérez D, López-Bellido R, Hidalgo JM, Rodríguez RE, Laorden ML, Núñez C, Milanés MV (2015) Morphine regulates Argonaute 2 and TH expression and activity but not miR-133b in midbrain dopaminergic neurons. Addict Biol 20:104-119

25. Glover EM, Davis M (2008) Anxiolytic-like effects of morphine and buprenorphine in the rat model of fear-potentiated startle: tolerance, cross-tolerance, and blockade by naloxone. Psychopharmacology 198:167-180

26. He Y, Wang ZJ (2012) Let-7 microRNAs and Opioid Tolerance. Front Genet 3:110 
27. He Y, Yang C, Kirkmire CM, Wang ZJ (2010) Regulation of opioid tolerance by let-7 family microRNA targeting the mu opioid receptor. J Neurosci 30:10251-10258

28. Hong SI, Nguyen TL, Ma SX, Kim HC, Lee SY, Jang CG (2017) TRPV1 modulates morphine-induced conditioned place preference via p38 MAPK in the nucleus accumbens. Behav Brain Res 334:26-33

29. Huang J, Wang J, Guo Q, Zou W (2019) Emerging roles of microRNAs in morphine tolerance. J Pain Res 12:1139-1147

30. Hutchinson MR, Shavit Y, Grace PM, Rice KC, Maier SF, Watkins LR (2011) Exploring the neuroimmunopharmacology of opioids: an integrative review of mechanisms of central immune signaling and their implications for opioid analgesia. Pharmacol Rev 63:772-810

31. Jacobsen JH, Watkins LR, Hutchinson MR (2014) Discovery of a novel site of opioid action at the innate immune pattern-recognition receptor TLR4 and its role in addiction. Int Rev Neurobiol 118:129-163

32. Jarvik LF, Simpson JH, Guthrie D, Liston EH (1981) Morphine, experimental pain, and psychological reactions. Psychopharmacology 75:124-131

33. Kelley AE, Domesick VB (1982) The distribution of the projection from the hippocampal formation to the nucleus accumbens in the rat: an anterograde- and retrograde-horseradish peroxidase study. Neuroscience 7:2321-2335

34. Kim J, Ham S, Hong H, Moon C, Im HI (2016) Brain Reward Circuits in Morphine Addiction. Mol Cells 39:645-653

35. Koller G, Schwarzer A, Halfter K, Soyka M (2019) Pain management in opioid maintenance treatment. Expert Opin Pharmacother 20:1993-2005

36. Koob GF, Volkow ND (2016) Neurobiology of addiction: a neurocircuitry analysis. Lancet Psychiatry 3:760-773

37. Law PY, Wong YH, Loh HH (2000) Molecular mechanisms and regulation of opioid receptor signaling. Annu Rev Pharmacol Toxicol 40:389-430

38. Lee B, Sur B, Yeom M, Shim I, Lee H, Hahm DH (2012) Effect of berberine on depression- and anxietylike behaviors and activation of the noradrenergic system induced by development of morphine dependence in rats. Korean J Physiol Pharmacol 16:379-386

39. Listos J, Łupina M, Talarek S, Mazur A, Orzelska-Górka J, Kotlińska J (2019) The Mechanisms Involved in Morphine Addiction: An Overview. Int J Mol Sci 20

40. Liu JG, Anand KJ (2001) Protein kinases modulate the cellular adaptations associated with opioid tolerance and dependence. Brain Res Brain Res Rev 38:1-19

41. Livak KJ, Schmittgen TD (2001) Analysis of relative gene expression data using real-time quantitative PCR and the 2(-Delta Delta C(T)) Method. Methods 25:402-408

42. Lowery-Gionta EG, Crowley NA, Bukalo O, Silverstein S, Holmes A, Kash TL (2018) Chronic stress dysregulates amygdalar output to the prefrontal cortex. Neuropharmacology 139:68-75 
43. Mah L, Szabuniewicz C, Fiocco AJ (2016) Can anxiety damage the brain? Curr Opin Psychiatry 29:56-63

44. Marcus DJ et al (2015) Tolerance to the antinociceptive effects of chronic morphine requires c-Jun N-terminal kinase. Mol Pain 11:34

45. McEwen BS, Morrison JH (2013) The brain on stress: vulnerability and plasticity of the prefrontal cortex over the life course. Neuron 79:16-29

46. Mercadante S, Arcuri E, Santoni A (2019) Opioid-Induced Tolerance and Hyperalgesia. CNS Drugs 33:943-955

47. Miladi-Gorji H, Rashidy-Pour A, Fathollahi Y (2012) Anxiety profile in morphine-dependent and withdrawn rats: effect of voluntary exercise. Physiol Behav 105:195-202

48. Motaghinejad M, Fatima S, Banifazl S, Bangash MY, Karimian M (2016) Study of the effects of controlled morphine administration for treatment of anxiety, depression and cognition impairment in morphine-addicted rats. Adv Biomed Res 5:178

49. Motaghinejad M, Karimian SM, Motaghinejad O, Shabab B, Asadighaleni M, Fatima S (2015) The effect of various morphine weaning regimens on the sequelae of opioid tolerance involving physical dependency, anxiety and hippocampus cell neurodegeneration in rats. Fundam Clin Pharmacol 29:299-309

50. Niu H et al (2017) Multi-system state shifts and cognitive deficits induced by chronic morphine during abstinence. Neurosci Lett 640:144-151

51. Ong WY, Stohler CS, Herr DR (2019) Role of the Prefrontal Cortex in Pain Processing. Mol Neurobiol 56:1137-1166

52. Quintero GC (2013) Role of nucleus accumbens glutamatergic plasticity in drug addiction. Neuropsychiatr Dis Treat 9:1499-1512

53. Raman M, Chen W, Cobb MH (2007) Differential regulation and properties of MAPKs. Oncogene 26:3100-3112

54. Ramos A (2008) Animal models of anxiety: do I need multiple tests? Trends Pharmacol Sci 29:493498

55. Robinson TE, Kolb B (2004) Structural plasticity associated with exposure to drugs of abuse. Neuropharmacology 47(Suppl 1):33-46

56. Robison AJ, Nestler EJ (2011) Transcriptional and epigenetic mechanisms of addiction. Nat Rev Neurosci 12:623-637

57. Rodríguez RE (2012) Morphine and microRNA Activity: Is There a Relation with Addiction? Front Genet 3:223

58. Roeska K, Doods H, Arndt K, Treede RD, Ceci A (2008) Anxiety-like behaviour in rats with mononeuropathy is reduced by the analgesic drugs morphine and gabapentin. Pain 139:349-357

59. Sartor GC, St Laurent G 3rd, Wahlestedt C (2012) The Emerging Role of Non-Coding RNAs in Drug Addiction. Front Genet 3:106 
60. Sepehrizadeh Z, Bahrololoumi Shapourabadi M, Ahmadi S, Hashemi Bozchlou S, Zarrindast MR, Sahebgharani M (2008) Decreased AMPA GluR2, but not GluR3, mRNA expression in rat amygdala and dorsal hippocampus following morphine-induced behavioural sensitization. Clin Exp Pharmacol Physiol 35:1321-1330

61. Sesack SR, Pickel VM (1990) In the rat medial nucleus accumbens, hippocampal and catecholaminergic terminals converge on spiny neurons and are in apposition to each other. Brain Res 527:266-279

62. Shin IC, Kim HC, Swanson J, Hong JT, Oh KW (2003) Anxiolytic effects of acute morphine can be modulated by nitric oxide systems. Pharmacology 68:183-189

63. Song P, Zhao ZQ (2001) The involvement of glial cells in the development of morphine tolerance. Neurosci Res 39:281-286

64. Spetea M, Asim MF, Wolber G, Schmidhammer H (2013) The $\mu$ opioid receptor and ligands acting at the $\mu$ opioid receptor, as therapeutics and potential therapeutics. Curr Pharm Des 19:7415-7434

65. Tian Q et al (2004) Integrated genomic and proteomic analyses of gene expression in Mammalian cells. Mol Cell Proteomics 3:960-969

66. Ueda $H$, Ueda $M$ (2009) Mechanisms underlying morphine analgesic tolerance and dependence. Front Biosci (Landmark Ed) 14:5260-5272

67. Valverde $O$ et al (2004) Modulation of anxiety-like behavior and morphine dependence in CREBdeficient mice. Neuropsychopharmacology 29:1122-1133

68. Wang $Y$ et al (2019) Opiate-associated contextual memory formation and retrieval are differentially modulated by dopamine D1 and D2 signaling in hippocampal-prefrontal connectivity.

Neuropsychopharmacology 44:334-343

69. Watkins LR, Hutchinson MR, Rice KC, Maier SF (2009) The "toll" of opioid-induced glial activation: improving the clinical efficacy of opioids by targeting glia. Trends Pharmacol Sci 30:581-591

70. Wilson-Poe AR, Jeong HJ, Vaughan CW (2017) Chronic morphine reduces the readily releasable pool of GABA, a presynaptic mechanism of opioid tolerance. J Physiol 595:6541-6555

71. Wu R, Li JX (2020) Toll-Like Receptor 4 Signaling and Drug Addiction. Front Pharmacol 11:603445

72. Yu G, Yan H, Gong ZH (2014) Effects of acute and repeated morphine treatment on k-opioid receptor protein levels in mesocorticolimbic system. J Recept Signal Transduct Res 34:44-47

73. Yuill MB, Zee ML, Marcus D, Morgan DJ (2016) Tolerance to the antinociceptive and hypothermic effects of morphine is mediated by multiple isoforms of c-Jun N-terminal kinase. Neuroreport 27:392-396

74. Zhang TJ, Qiu Y, Hua Z (2019) The Emerging Perspective of Morphine Tolerance: MicroRNAs. Pain Res Manag 2019:9432965

75. Zhang X, Cui Y, Jing J, Cui Y, Xin W, Liu X (2011a) Involvement of p38/NF-kB signaling pathway in the nucleus accumbens in the rewarding effects of morphine in rats. Behav Brain Res 218:184-189 
76. Zhang $Y$ et al (2011b) Essential role of toll-like receptor 2 in morphine-induced microglia activation in mice. Neurosci Lett 489:43-47

\section{Tables}

Table 1. Scoring of naloxone-precipitated withdrawal signs, including graded and checked signs.

\begin{tabular}{|c|c|c|c|}
\hline Type of Signs & Symptoms & No. & Weighing Score \\
\hline \multirow[t]{8}{*}{ Graded Signs } & Rearing & $<30$ & 1 \\
\hline & & $30-40$ & 2 \\
\hline & & $\geq 40$ & 3 \\
\hline & Jumping, Writhing, & $1-4$ & 1 \\
\hline & and Rubbing & $5-9$ & 2 \\
\hline & & $\geq 10$ & 3 \\
\hline & Wet-dog shake & $1-2$ & 2 \\
\hline & & $\geq 3$ & 3 \\
\hline \multirow[t]{5}{*}{ Checked Signs } & Ptosis & + & 2 \\
\hline & Diarrhea & + & 2 \\
\hline & Chattering & + & 2 \\
\hline & Genital grooming & + & 3 \\
\hline & Irritability & + & 3 \\
\hline
\end{tabular}

Rearing: Lifting the forepaws off the ground and standing on the hind paws; Jumping: Attempt to escape out of the chamber; Writhing: Abdominal stretching; Rubbing: Moving the jaw or the torso on the ground; Wet-dog shake: Shaking of the whole body; Ptosis: Squinting of the eyes; Diarrhea: Watery or unshaped feces; Chattering: Teeth grinding or rapidly opening-closing of jaws; Genital grooming: Evidence of licking of the genital; Irritability: Attack or vocalization when touched at the end of the period.

Table 2. Primers used for real-time PCR 


\begin{tabular}{|c|c|c|}
\hline Gene & Sequences $\left(5^{\prime}-3^{\prime}\right)$ & Amplicon size (bp) \\
\hline \multirow[t]{2}{*}{ Gapdh } & F: AGTGCCAGCCTCGTCTCATA & 77 \\
\hline & R: GTAACCAGGCGTCCGATAC & \\
\hline \multirow[t]{2}{*}{$\| 1$} & F: CAGGATGAGGACCCAAGCAC & 74 \\
\hline & R: TCATCCCACGAGTCACAGAGG & \\
\hline \multirow[t]{2}{*}{ Tnfa } & F: AAATGGGCTCCCTCTCATCAGTTC & 111 \\
\hline & R: TCTGCTTGGTGGTTTGCTACGAC & \\
\hline \multirow[t]{2}{*}{$1 / 6$} & F: AGCGATGATGCACTGTCAGA & 127 \\
\hline & R: GGAACTCCAGAAGACCAGAGC & \\
\hline \multirow[t]{2}{*}{$\| 1 r 1$} & F: ACAGGGACTCCTGCTCTGAT & 95 \\
\hline & R: TCCCTCTCCGTAGGTCTTGG & \\
\hline \multirow[t]{2}{*}{ Tnfrs1a } & F: TACGGATCCCTCAACCCTGTG & 115 \\
\hline & R: CCACAGCATACAGCATCGCAG & \\
\hline \multirow[t]{2}{*}{ II6r } & F: CCATCAGGGTCCCATAACAGC & 95 \\
\hline & R: TTGCTGTTGTCATTAGGGCAC & \\
\hline \multirow[t]{2}{*}{ TIr1 } & F: CTGCTTTGGGGAGCAACAAC & 130 \\
\hline & R: AACACTAGTGGCACAGTCGG & \\
\hline \multirow[t]{2}{*}{ TIr4 } & F: CCCTGCCACCATTTACAGTTCG & 96 \\
\hline & R: GAGTCCCAGCCAGATGCAAGAG & \\
\hline \multirow[t]{2}{*}{ Erk1 } & F: CCAAACAAGCGCATCACAGT & 82 \\
\hline & R: CCACTGGTTCATCTGTCGGA & \\
\hline \multirow[t]{2}{*}{ p38a } & F: TGACGAAATGACCGGCTAC & 104 \\
\hline & R: AGCCCACGGACCAAATATC & \\
\hline \multirow[t]{2}{*}{ Jnk3 } & F: GCTACAAGGAGAACGTGGAC & 132 \\
\hline & R: ACGGAGTTCCTAGCTGCTCTA & \\
\hline \multirow[t]{2}{*}{ Creb1 } & F: CTGAGGAGCTTGTACCACCG & 127 \\
\hline & R: AATCTGTGGCTGGGCTTGAA & \\
\hline \multirow[t]{2}{*}{ Nfkb1 } & F: TTACGGGAGATGTGAAGATG & 94 \\
\hline & R: ATGATGGCTAAGTGTAGGAC & \\
\hline Fos & F: GGAGCCGGTCAAGAACATTA & 74 \\
\hline
\end{tabular}




\begin{tabular}{|lll|}
\multicolumn{3}{|c|}{ R: ATGATGCCGGAAACAAGAAG } \\
Let7c1 & F: GTGCATCCGGGTTGAGGTAG & \\
& R: GCTCCAAGGAAAGCTAGAAGGT & \\
\hline mir-133 & F: CTGCTCTGGCTGGTCAAACG & 73 \\
& R: CTGCTGTAGCTGGTTGAAGGG \\
\hline mir-365 & F: ACAGCAAGAAAAATGAGGGAC & 72 \\
& R: GGATTTTTAGGGGCATTATGAC \\
\hline
\end{tabular}

Gapdh: Glyceraldehyde-3-phosphate Dehydrogenase; II1: Interleukin 1 ; Tnfa: Tumor necrosis factor a; II1r1: Interleukin 1 receptor type 1; Tnfrs1a: TNF receptor superfamily member 1A; TIr1: toll-like receptor 1; TIr4: Toll-like receptor 4; Erk1: Extracellular signal-regulated kinase 1 (MAPK3); p38a: p38a MAP kinase (MAPK 14); Jnk3: c-Jun N-terminal kinase 3 (MAPK 10); Creb1: cAMP response element-binding protein 1; Nfkb: Nuclear factor kappa B subunit 1; Fos: Fos proto-oncogene, AP-1 transcription factor subunit; mir133b: pre-miRNA133b; mir-365: pre-miRNA-365.

\section{Figures}


- Saline $(1 \mathrm{ml} / \mathrm{kg})$

- Morphine $(10 \mathrm{mg} / \mathrm{kg})$
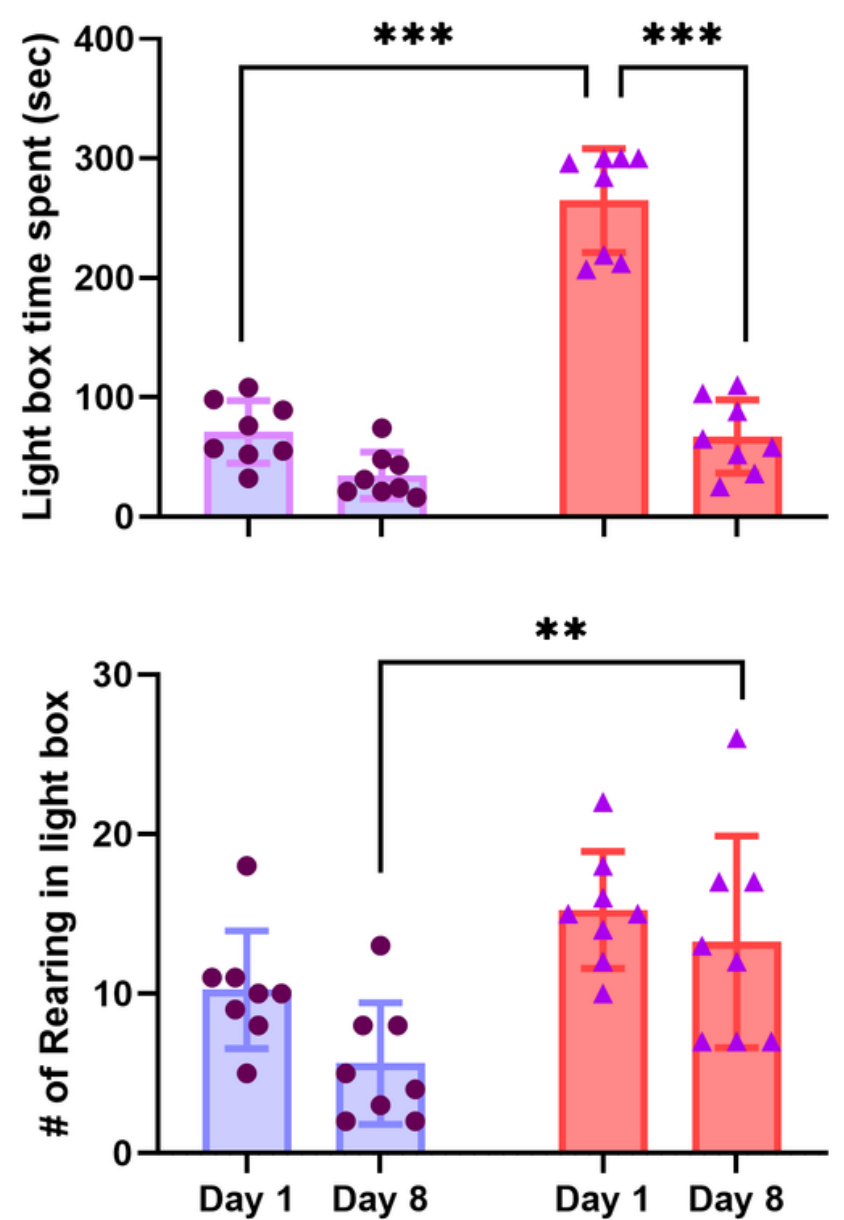

Days of repetaed injection
- Saline $(1 \mathrm{ml} / \mathrm{kg})$

\ Morphine $(10 \mathrm{mg} / \mathrm{kg})$
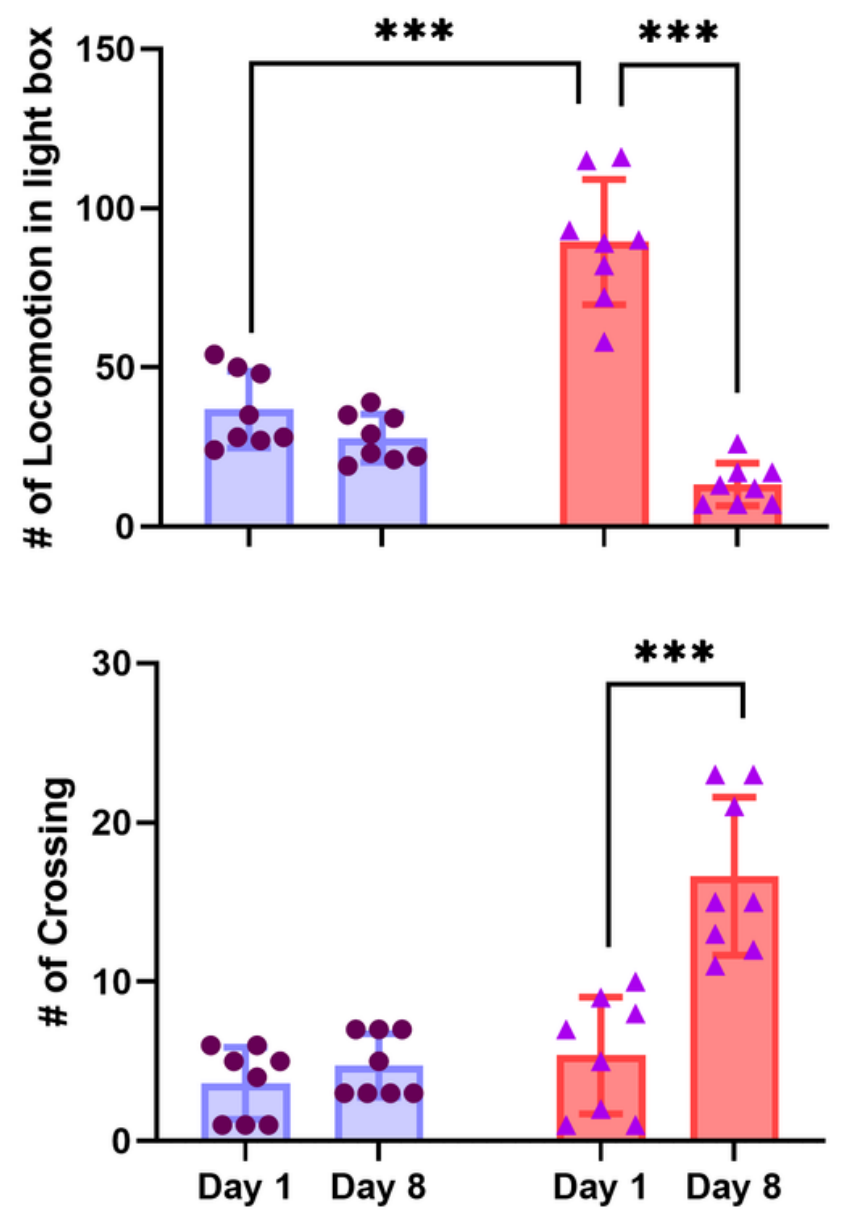

Days of repetaed injection

Figure 1

Repeated injection of morphine induces anxiety-like behaviors. Two experimental groups $(n=8)$ received either saline $(1 \mathrm{ml} / \mathrm{kg})$ or morphine $(10 \mathrm{mg} / \mathrm{kg})$ twice a day for eight consecutive days. Anxiety-like behaviors in a light/dark box test, including lightbox time spent, locomotor activity, rearing, and crossing or transitions between the two light and dark chambers were assessed on days 1 and 8 of the injections. Each bar represents the mean \pm SD of the specified behavior in each group on a respective day. Dots and triangles on the bars represent the individual data in each group. ${ }^{*} \mathrm{P}<0.01$ and ${ }^{\star \star *} \mathrm{P}<0.001$ compared with the specified group. 

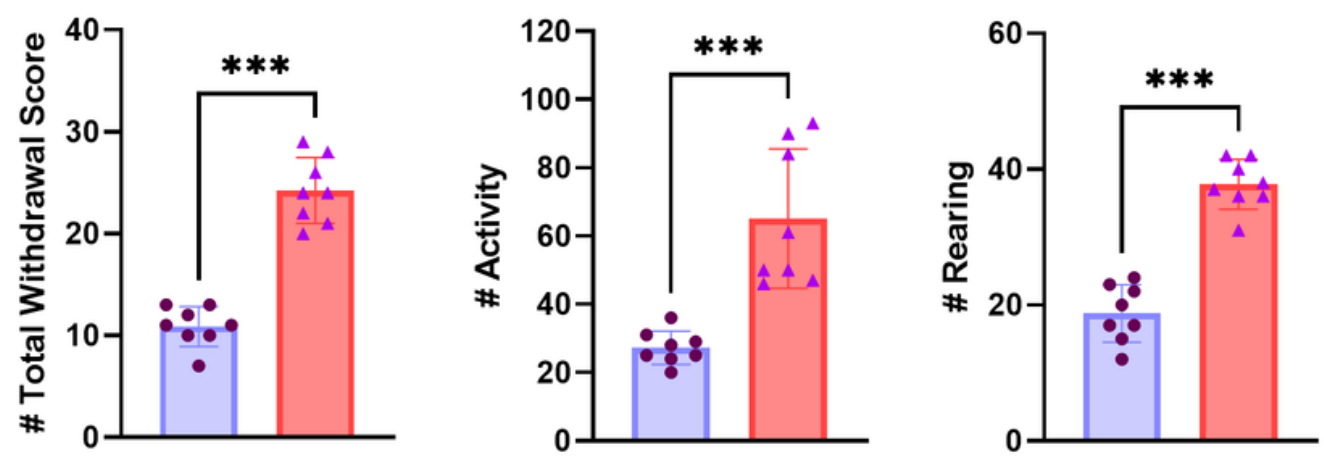

- Saline + Naloxone

4 Mor $10+$ Naloxone
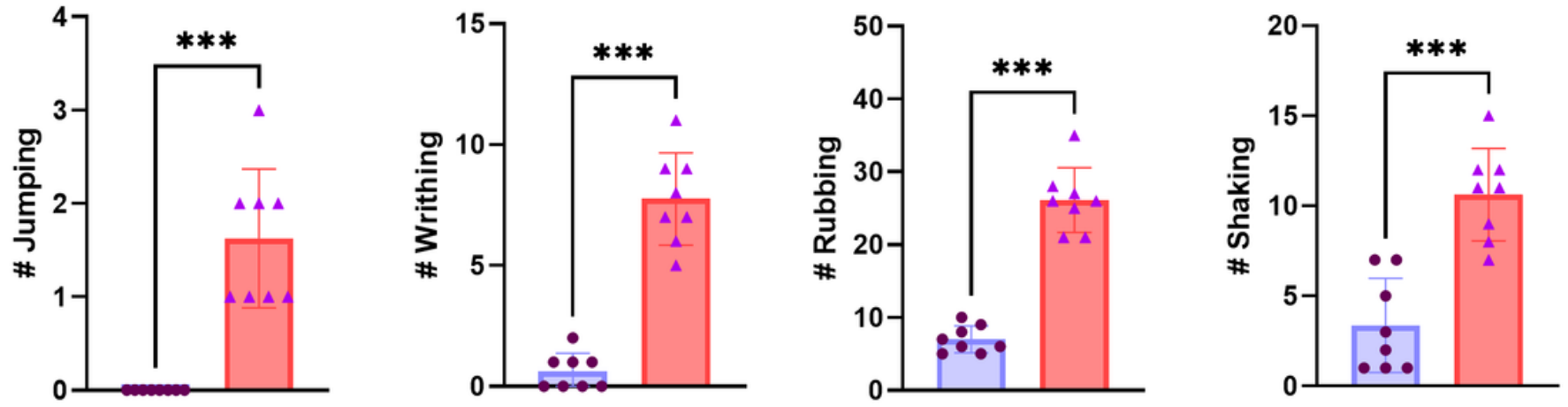

Figure 2

Repeated injection of morphine for eight days induced drug dependence. On day 8 of the repeated injection, naloxone precipitated withdrawal symptoms were assessed immediately after injection of naloxone ( $1 \mathrm{mg} / \mathrm{kg}$, i.p.). Naloxone was injected $4 \mathrm{~h}$ after the injection of saline or morphine at the morning session. Each bar represents the mean \pm SD of the specified sign of withdrawal in each group. Circle dots and triangles on the bars represent the individual data in each group. ${ }^{\star \star \star} P<0.001$ compared with the control group. 
TLR1

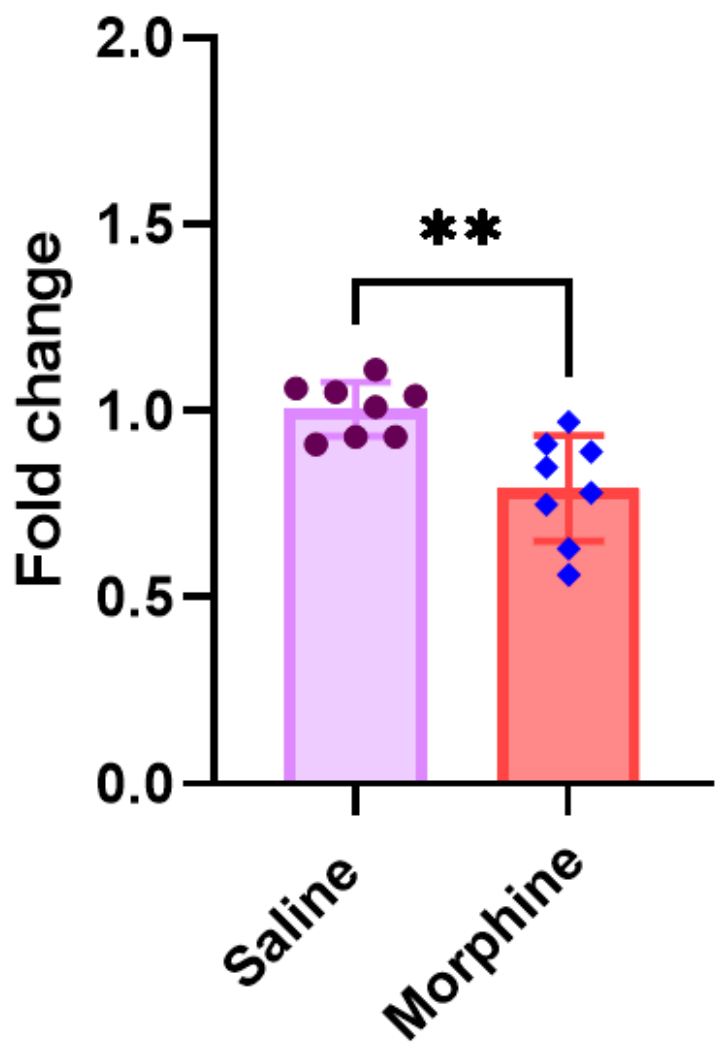

TLR4

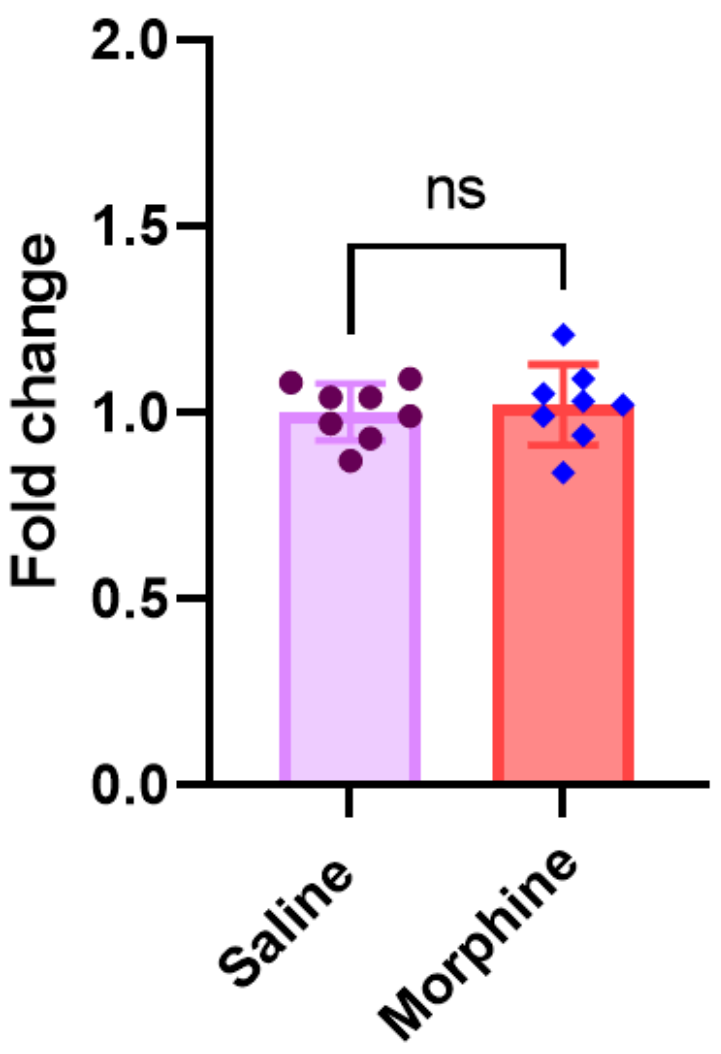

Figure 3

Gene expression of Toll-like receptors in the PFC after the induction of morphine dependence. Gene expression of toll-like receptors, including TIr1 and TIr4, were examined in the PFC on day 8 of the repeated injection. Each bar represents the mean \pm SD of the gene expression data in each experimental group. Circle dots and diamond shapes on the bars represent the individual data in each group. ${ }^{* *} \mathrm{P}<$ 0.01 compared with the control group. 
IL1
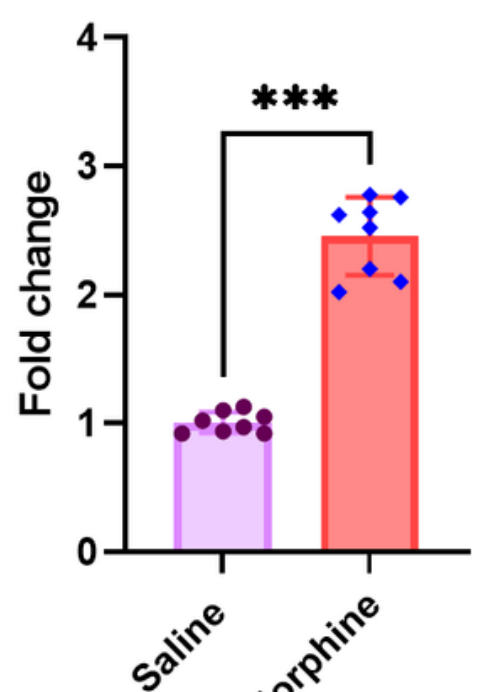

IL1R

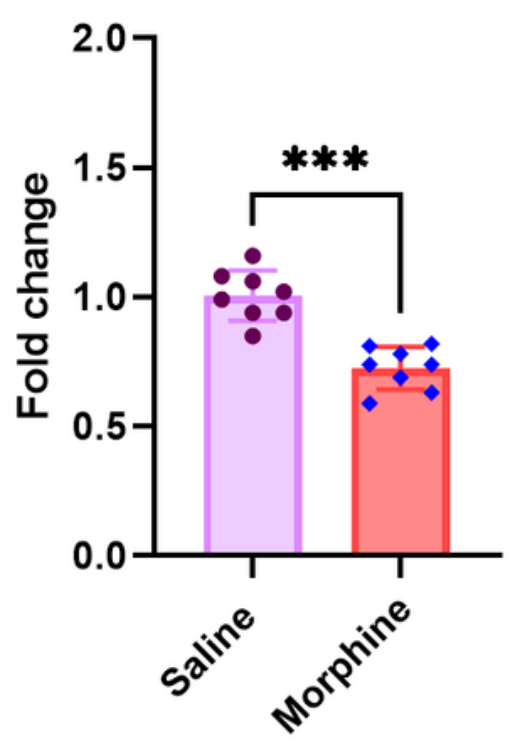

TNF
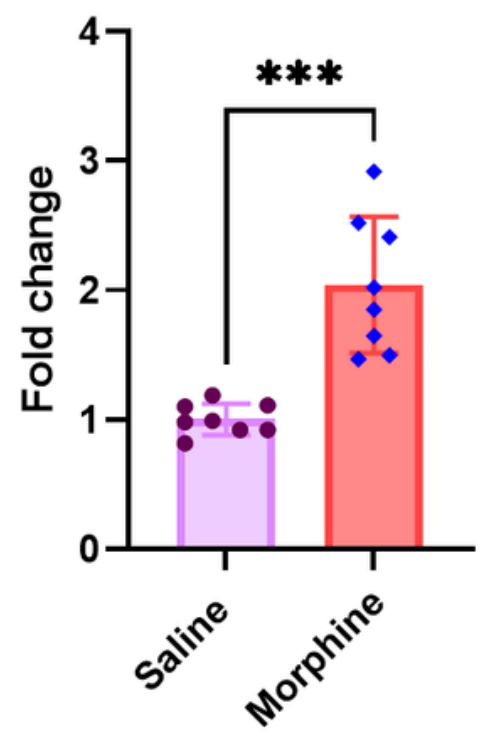

TNFR

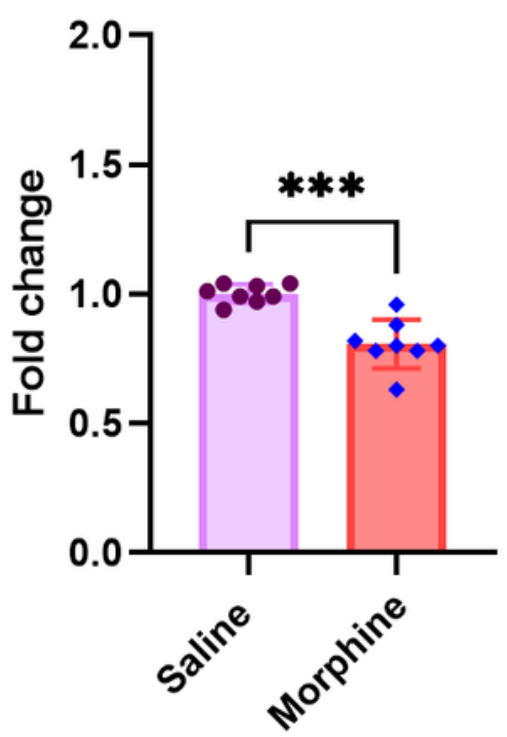

IL6

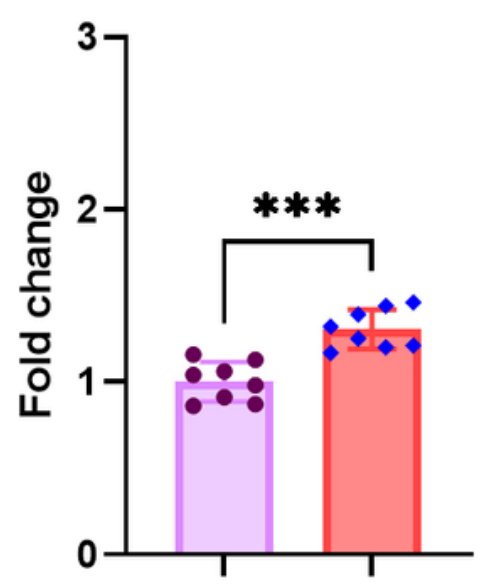

IL6R

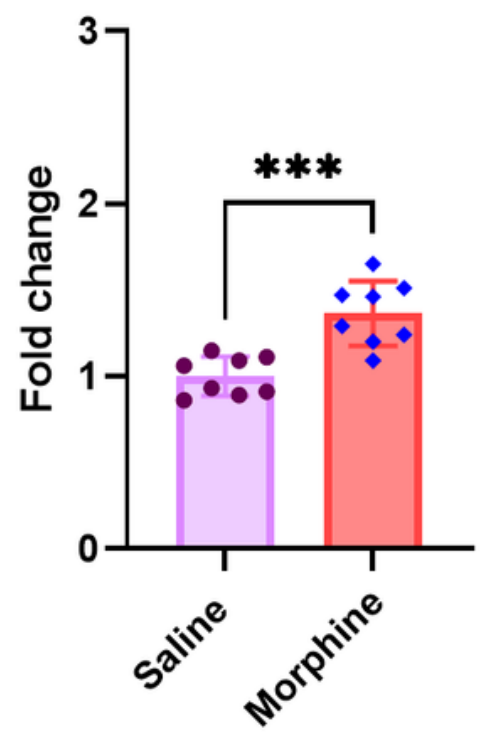

\section{Figure 4}

Gene expression of proinflammatory cytokines in the PFC after morphine dependence. Gene expression of proinflammatory cytokines, including $\| 1$, Tnfa, $\| 6$, and their respective receptors, including $\| 1 \mathrm{r}$, Tnfr, and $\| 6 \mathrm{r}$ were examined in the PFC on day 8 of the repeated injection. Each bar represents the mean \pm SD of the gene expression data in each experimental group. Circle dots and diamond shapes on the bars represent the individual data in each group. ${ }^{\star * *} \mathrm{P}<0.001$ compared with the control group. 
ERK1/2

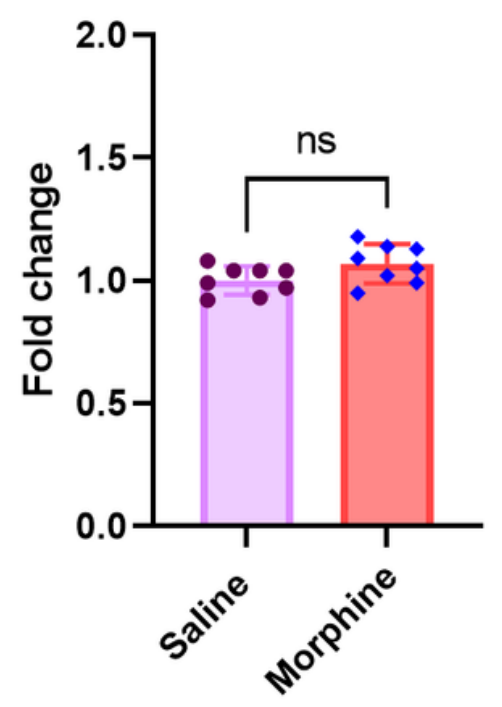

p38

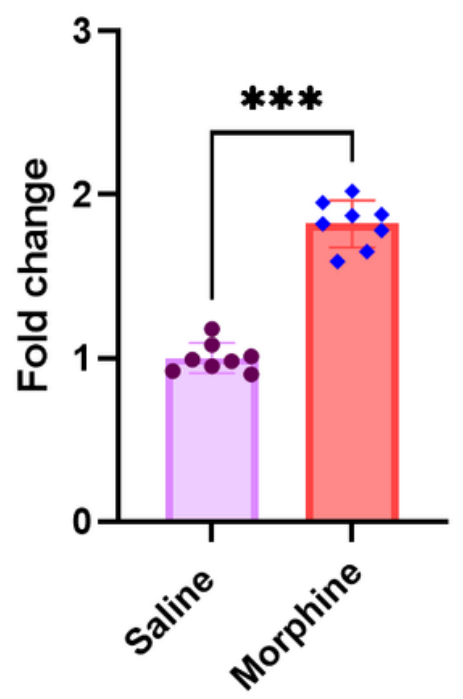

Jnk3

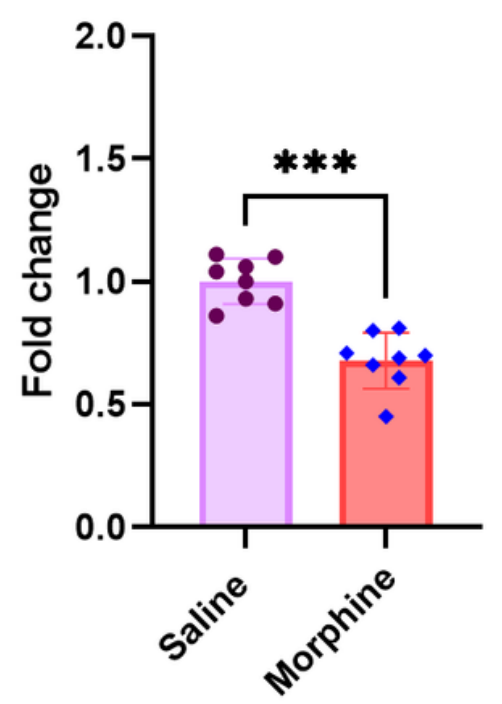

\section{Figure 5}

Gene expression of MAPKs in the PFC after the induction of morphine dependence. Gene expression of three MAPKs, including Erk1, p38, and Jnk3 were evaluated in the PFC on day 8 of the repeated injection. Each bar represents the mean \pm SD of the gene expression data in each experimental group. Circle dots and diamond shapes on the bars represent the individual data in each group. NS indicates no significant statistical group difference. ${ }^{* \star *} \mathrm{P}<0.001$ compared with the control group. 


\section{CREB}

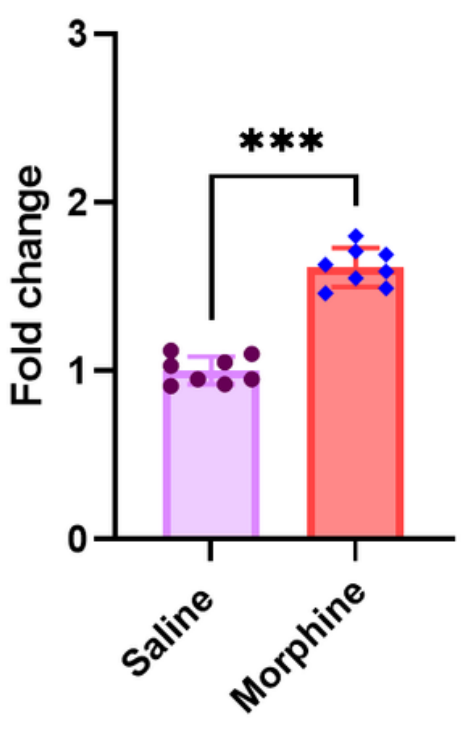

NF-kB

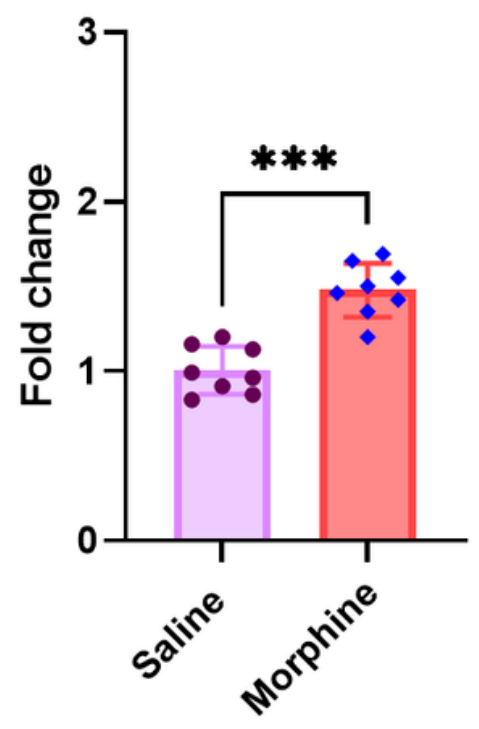

FOS

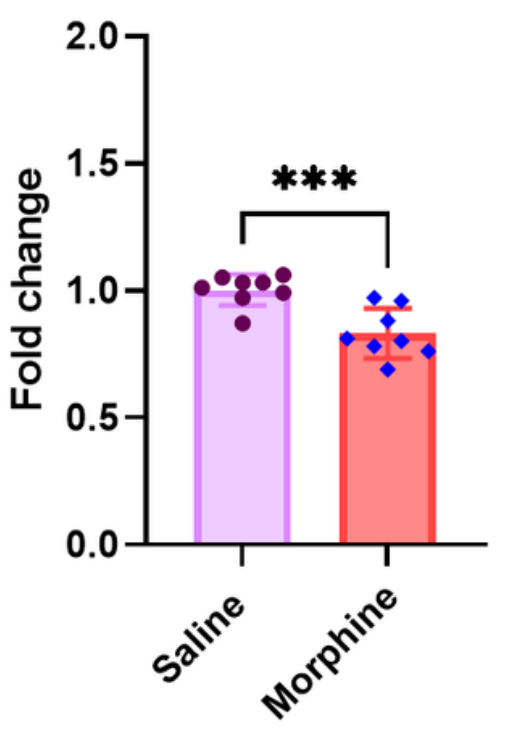

Figure 6

Gene expression of transcription factors, including Creb, Nfkb, and Fos in the PFC after the induction of morphine dependence. Gene expression of three transcription factors, including Creb, Nfkb, and Fos were evaluated in the PFC on day 8 of the repeated injections. Each bar represents the mean \pm SD of the gene expression data in each experimental group. Circle dots and diamond shapes on the bars represent the individual data in each group. ${ }^{\star \star \star} \mathrm{P}<0.001$ compared with the control group. 
Let-7c

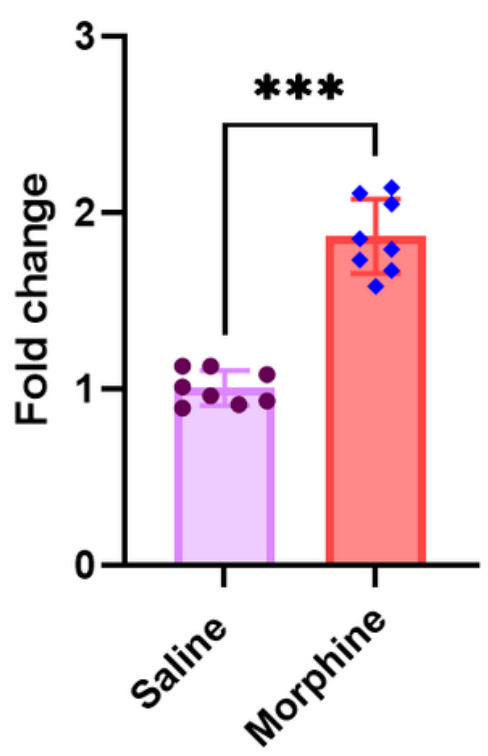

$\operatorname{mir}-133 b$

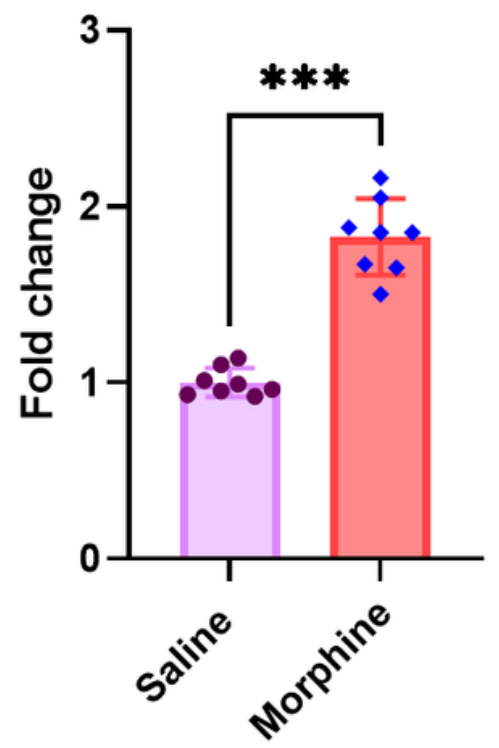

mi-365

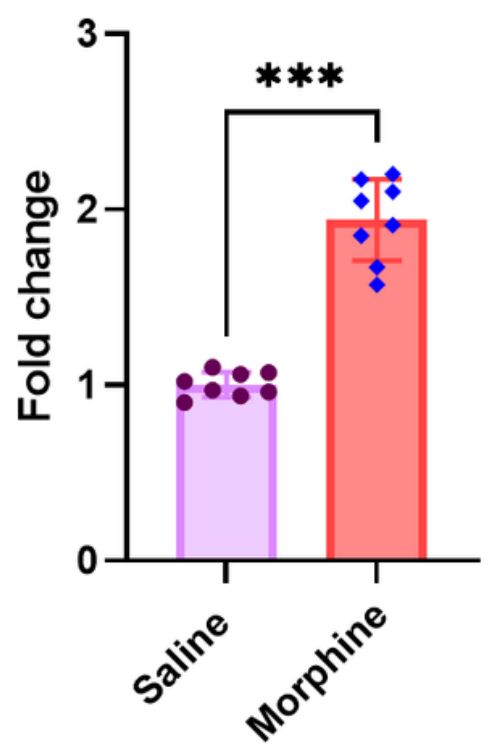

\section{Figure 7}

Effect of repeated morphine injection on the expression of Let7c1, mir-133b, and mir-365 in the PFC after induction of morphine dependence. Expression of three pre-miRNAs, including let-7c, mir-133b, and mir365 were examined in the PFC on day 8 of the repeated injection. Each bar represents the mean \pm SD of the gene expression data in each experimental group. Circle dots and diamond shapes on the bars represent the individual data in each group. ${ }^{\star \star \star} \mathrm{P}<0.001$ compared with the control group. 